\title{
Analysis on the Practical Application of Multiple Incentive Mechanism in Educational Management
}

\author{
Yanjun Huang* \\ Xi'an Technological University, Xi'an 710021, Shaanxi Province, China \\ *Corresponding author: Yanjun Huang, 446215964@qq.com
}

\begin{abstract}
In the new era, China's education industry was ushered in a high-quality development stage. On the one hand, it is necessary to set a goal of education management on the all-round development of students. On the other hand, we should innovate some practical application schemes of diversified incentive mechanism consistent with the needs of educational management. Taking this as the starting point, this paper summarizes the connotation of incentive mechanism and diversified incentive mechanism, and analyzes the practical problems of single incentive standard, issues on incentive timeliness, and reduced participation of incentive objects at the current stage. On this basis, this paper puts forward some corresponding measures from three angles: opening up thinking, updating in time and emphasizing the target.
\end{abstract}

Keywords: Education management; Multiple incentive mechanism; Practical application

Publication date: December 2021; Online publication: December 27, 2021

\section{Introduction}

Modern education management, which involves both teachers and students, is necessary for improving the quality of education by stimulating the internal potential of teachers and students. From the perspective of the methods adopted in the practice of educational management, incentive measures still occupy the mainstream position and play a great role ${ }^{[1]}$. However, since the "new-generation" students are experiencing development in diversified aspects, it is necessary to expand the current incentive mechanism in combination with the actual needs of students in educational management, so as to establish a practical scheme of diversified incentive mechanism with a higher matching degree. The specific analysis is as follows:

\section{Overview of multiple incentive mechanism}

\subsection{Incentive mechanisms}

From the perspective of concept definition, the incentive mechanism mainly starts from the perspective of management and enhances the commitment of incentive objects under a fixed management system. As different industries and organizations apply incentive mechanisms in a relatively consistent way, the incentive mechanism is endowed with standardized and immobilized characteristics. Through the intermediary role of the incentive mechanism, the subject and object of the incentive mechanism can establish a kind of interaction, develop mutual restriction, and finally realize the management goal.

\subsection{Multiple incentive mechanism}

Diversified incentive mechanism is mainly based on incentive mechanism, combined with management practice needs and experience, and under different incentive paths, we should select more applicable incentive measures or means to maximize the utility of incentive mechanism after application ${ }^{[2]}$. We can 
take education management as an example. When implementing the diversified incentive mechanism, on the one hand, we can choose the determined management object to independently motivate teachers or students to form a diversified incentive scheme. On the other hand, it can also carry out incentive activities through funds, further education, professional titles, credits and honors under different incentive paths ${ }^{[3]}$. From the current practice mode of diversified incentive mechanism, management practice attaches great importance to two-way communication, respective selection, phased evaluation, year-end evaluation and incentive distribution, as well as comparison and re-communication. Thus, it also tends to rationalize the multiple incentive mechanisms.

\section{Problems in practical application of multiple incentive mechanisms in educational management 3.1. Single incentive standard}

At present, under the guidance of the general goal of quality education, all colleges highlight the two main bodies of teachers and students in education management. However, in the process of implementing the multiple incentive mechanism the incentive content is gradually expanding with the gradual changes of teachers' teaching needs and students' learning needs. In short, after entering the new era, the diversified incentive content in China's higher education management has been expanded. However, under such conditions, the incentive standard is relatively single, and the progress in the formulation of quality system management standard is slow ${ }^{[4]}$.

From the perspective of the reasons, it is mainly because after the participation of China's education industry in the global education industry, it has developed a more applicable quality system management standard based on the standard of the international education management and it fulfills the actual management needs of the education industry in the local market. However, in terms of multiple incentive mechanisms, different colleges and universities are affected by the scale of educational institutions, educational majors, teaching stratification objectives and so on. The quality system management standards in educational management cannot fully comply with the requirements of the actual incentive standards. Therefore, some colleges and universities have adopted the method from experience accumulation and refinement to incentive standard setting. The practice of this method needs a process, which leads to followup inadequacy and adoption of a relatively single incentive standard.

\subsection{Poor incentive timeliness}

Whether it is a conventional standardized incentive mechanism or a diversified incentive mechanism, the principle of timely incentive in management should be followed in practical application. For example, after the students complete various assessments, teachers need to give timely incentives to students, so as to ensure that students consolidate their internal passion and enthusiasm under the condition of timely incentives, and assist students to more actively carry out follow-up learning activities.

The time-sensitive incentive is characterized by persistence. When the school adopts an incentive duration of half a year or even one year, the incentive effect will be greatly reduced, resulting in a "study hard" mentality, which makes students pay less attention to the incentive results. Especially when some colleges and universities adopt the final evaluation scheme, the value of some honor incentive will be weakened as students are engaged in assignments that are assessed real-time. Similarly, under the diversified incentive mechanism, certain punishment measures are also set up. But at this stage, the "positive reinforcement" is strengthened, the "negative reinforcement" is reduced, and even some colleges and universities cancel the punishment measures in the "negative reinforcement," contributing to the decline of students' attention to multiple incentives. Therefore, from the current demand for the practical application of educational management, we should moderately weaken the "negative reinforcement" and scientifically adjust the "positive reinforcement." This can help the incentive mechanism attain an 
appropriate management standard.

\subsection{Reduced participation of incentive objects}

For most colleges and universities, multiple types are also set up under the diversified incentive mechanism. However, on the whole, the type of incentives available is scanty. As a result, the incentive objects competite for some fixed incentive types. For example, most students set their incentive goals on scholarships and grants, and their expectations for honor incentive and further education incentive are relatively low. For another example, in education management, group incentive, class incentive, entrepreneurship incentive, international exchange student incentive and other aspects can be further differentiated into more detailed packages. However, for some colleges and universities, the diversified incentive mechanism in educational management still fails to reach this level. Therefore, the incentive objects gradually give up in pursuing incentives, thereby reducing their participation in the fierce competition.

Phased incentive is a problem in the process of incentive object participation. As an individual, students themselves are in a state of development. At different stages, they need some incentive measures to help them complete the growth of the transition stage. If the phased incentive is not available and when some difficulties cannot be resolved in time, so the students will become disappointed, as their expectations cannot not be met, thereby reducing the number of participation in incentive, and becoming reluctant to promote their own development towards a sound personality and a more perfect knowledge structure through the incentive mechanism.

\section{Countermeasures of practical application of multiple incentive mechanisms in educational management}

\subsection{Mind open-up and increase of incentive standard}

It is suggested that in education management, we should adopt the industrial chain method that has been widely applied in the reform in recent years, and clearly divide the research, development and design domain, resource processing domain, product innovation domain, product application domain, product feedback domain, and product optimization domain of education management products from the perspective of production and manufacturing of education management products. It is necessary to build an education management industry chain with complete content and clear process. On the other hand, according to the industrial chain of educational management product production and manufacturing, incentive measures matching each domain should be set. In this way, the incentive standard can be increased more accurately according to the constituent elements of each domain.

Specifically, under the conditions of the clear definition of the various domains of the industrial chain, we can make a list of educational management elements, corresponding to the list of educational management elements, set up the evaluation and assessment indicators under the multiple incentive mechanism, and form the corresponding relationship between educational management elements and educational management indicators, so as to effectively apply multiple incentive mechanisms. In addition, after determining the path from theory to experience combined with the path from experience to theory, we should refine the application experience of the incentive mechanism of education management, and then innovate some incentive measures that fully match the practical application needs, and continuously improve the multiple incentive schemes of education management.

\subsection{Timely update and improving incentive timeliness}

When the multiple incentive mechanism is applied, it should be timely, clear and continuous in order to effectively strengthen the function of the incentive mechanism. For example, in terms of student motivation, 
we can sort out the real needs of students from the basic characteristics of "new-generation" students, including eliminating the false items and preserving the true items, improving personality, optimizing knowledge structure and so on. In this way, it is conducive to further setting incentive objectives according to multiple needs, such as setting honor incentive, capital incentive, further study incentive, exchange student incentive, entrepreneurship incentive and other incentive that matches the results of comprehensive quality assessment.

In order to ensure the realization of incentive timeliness, it is suggested to adopt project management methods to implement systematic and complete application of each type of incentive scheme. For example, based on Skinner's reinforcement theory and Premark's principle, reinforcement means ("positive reinforcement" and "negative reinforcement") are set and high-frequency and low-frequency behaviors are divided. Then, according to the specific learning projects, teaching projects, competition projects, entrepreneurship projects, design projects, etc., the principle of "timely, clear and continuous" is implemented into the incentive scheme corresponding to the specific project, so as to achieve the effect of strengthening the two main bodies of incentive education management.

\subsection{Emphasis on the objectives and improving enthusiasm for participation}

At present, the application scope of diversified incentive mechanism in education management is relatively wide. It is suggested that when the overall goal is determined, clear hierarchical objectives should be decomposed according to the equal rights and responsibilities mechanism as far as possible. In this way, it is conducive to the clarification of the incentives for teachers and students. Especially in the phased incentive process, we can choose different courses, different grades and other perspectives to highlight the guiding role of incentive objectives, so as the two subjects in educational management can participate in the actual application process of incentive mechanism. In short, emphasizing the incentive goal can make the educational subject to actively participate in the educational management activities under the incentive process of "setting clear goal - achieving corresponding effort - making teaching evaluation - obtaining incentive - setting new goal."

\section{Conclusion}

In short, the role of incentive mechanism in education management is crucial. Through the above preliminary analysis, it can be seen that the diversified incentive mechanism is the innovation and expansion based on the incentive mechanism. However, the supports for incentive standards, set-up and follow-up of incentive standards, incentive timeliness and incentive object participation under the multiple incentive mechanism are insufficient, leading to a phenomenon in which the multiple incentive mechanism cannot achieve the expected goal in the application process. Therefore, it is suggested that in the current highquality development stage of education management, we should absorb previous reform experience, increase some incentive standards, strengthen incentive timeliness, and improve the participation enthusiasm of incentive objects, so as to achieve the goal of improving the efficiency of education management.

\section{Disclosure statement}

The author declares no conflict of interest.

\section{References}

[1] Yang L, 2020, Visual Analysis of Educational Management Research of Ethnic Minority Students in Colleges and Universities. The Party Building and Ideological Education in Schools, 14(20): 57-59. 
[2] Yu K, Yang S, 2020, Paradigm Issues and Methodological Change in Educational Management Research: A Technical Initiative. Journal of Educational Studies, 16(5): 36-42.

[3] Zhang S, Zhao Y, 2020, Visual Exploration of Intelligent Education Management System - A Case study of Hunan University of Technology and Business. Modern Educational Technology, 30(8): 8085.

[4] Wang X, Liu G, 2020, Research on College Students' Educational Management Ecosystem in MicroEra. Contemporary Youth Research, 19(1): 30-36. 